\title{
Using ICQ to enhance teacher-student relationships
}

\author{
Suky Shung King Yin \\ The University of Hong Kong \\ Sue Trinidad \\ Curtin University of Technology
}

\begin{abstract}
This research investigated the use of computer mediated communication $(\mathrm{CMC})$ tools to enhance teacher-student relationships in two secondary schools in Hong Kong. This study showed that ICQ (a most popular CMC tool) could be used to enhance teacher-student relationships in these cases. An ethnographic approach was used where the interviews were conducted with key informants, face to face $(n=11)$ and then through ICQ $(n=4)$. Teachers who used ICQ to communicate with students were also interviewed $(n=4)$. It was found in this study that the school and the parents over-stressed academic achievement, with both teachers and students being required to spend most of their time on academic related matters, and as such the results were that teacher-student communication was found to be rare in the two school environments. The study was able to summarise why students prefer using ICQ to communicate with teachers, how the Confucian heritage culture affects teacher-student communication in Hong Kong schools, and how ICQ can be used to enhance teacher-student communication.
\end{abstract}

\section{Background}

Young people are no longer content with unidirectional teaching since they have learnt to use the Internet proactively and therefore it appears that the Internet has a very important role in teaching and learning in the future. Due to the development of computer networks in Hong Kong schools, teachers are more likely to use information and communications technology (ICT) routinely in classrooms but many of them have not realised the potential of computer mediated communication (CMC) with students outside of the classroom. As the role of the teacher is changing, it is an ideal time for teachers to investigate and adopt different modes of communication with their students. Tu Po Ji Gou (2000) reported that over fifty percent of local Hong Kong students enjoy using a popular CMC tool 
called ICQ as the medium of communication. ICQ not only enhances interpersonal communication but also provides a channel for youths to express their ideas freely.

Hong Kong is a society that is mixed with a long tradition of Chinese culture and Western cultures. On the one hand, beliefs and thinking of the Hong Kong people are greatly affected by the Chinese culture, and on the other hand, Hong Kong people are affected by current social and educational conditions. The Western culture is different from that of the Chinese culture and many teenagers are struggling in this mixed cultural environment. Due to the impact of the Western culture, there has been a growing number of teenagers trying to break free from traditional cultural constrains, and ICQ is perceived as a tool to satisfy their desires and needs for boundless communication. As the Internet and CMC become more important in education, this study concentrated on investigating the impact of ICQ on teacher-student communication in two Hong Kong secondary schools.

\section{What is ICQ?}

ICQ is perceived as a well-established communication network throughout the world. ICQ is a revolutionary, user friendly, Internet based communication program that tells the user who is online at any time. ICQ alerts the user when friends or colleagues sign on. With ICQ, you can chat, send messages and files, play games or communicate with your friends while still surfing the Internet. As the product website states:

ICQ is a way to communicate. As the name implies, ICQ or 'I Seek You' is simply a way of getting in touch with people and friends. ICQ makes it easy to find people with similar interests across the globe, to establish new friendships, to communicate with colleagues, family members and friends no matter when or where they are. Once friendships and connections have been established you just need to go online to get in contact without the geographic and time related limitations of the offline world.... The most popular method of communication on ICQ is instant messaging, enabling you to send a message that immediately pops up on an online contact's screen. ... With ICQ Instant Messenger you can video/audio chat, send email, SMS and wireless pager messages, as well as transfer files and URLs. [http:/ / www.icq.com/ products/ whatisicq.html]

\section{Why Confucian heritage culture affects teacher-student communication}

From preliminary observations in a Hong Kong school, it was noted that students with behavioural problems were more willing to talk to the teacher through ICQ, as they could then approach the teacher proactively 
on their own terms and without shame or ridicule from their peers, which can happen in a face to face situation. In contrast to this, those students who have a higher academic achievement were noted to be more passive, and they only approached the teacher when they encountered problems in their studies. It was proposed that if teachers could make use of an online communication channel like ICQ to access and facilitate student learning, then this could be a very powerful tool in teacher-student communication. At the same time, this becomes an important issue for teachers because ICQ might be a preventive measure to communicate with students and understand their problems and provide solutions. It is believed that the way of communication of students is closely related to the culture and the background in which they have grown up.

Most Hong Kong students have grown up in a Confucian heritage culture. In a Confucian heritage culture, the major role is to maintain the harmony of the society. 'Filial piety' is one of the major concepts in the Chinese society that not only affects the way of bringing up a child but also affects the way and attitude of how teenagers communicate with the elders $(\mathrm{Li}$, 1995). The 'family' is basic unit of the society, and there is a rigid system that rules the status of each member in the family in a Confucian society. The younger ones must respect the elderly and obey what the elderly say. Most of the time, the way of communication in a family is unidirectional, children have to follow the instructions of their parents and it is rare for them to express their own ideas, as any objection from the children would be perceived as breaking the rules of filial piety (Ho, 1994; Ho, Peng \& Chan, 2001; Pang, 2000).

Confucian heritage culture also emphasises the importance of social relationships and collectivism. Teacher-student communication is intimately affected by Confucian heritage culture. Even if the students are willing to communicate with teachers, it was observed by the researchers that students are not willing to talk to teachers openly. In school, the primary goal is to maintain group harmony. Chinese students are taught to avoid conflict within a group; in order to achieve this goal, Chinese students avoid criticising their group members or voicing out their own ideas. Even when it is necessary to express their own ideas, students tend to be humble, self effacing, and avoid directly conveying their own point of view, they suggest rather than state directly, in order to avoid being seen as too individualistic. On the whole, Chinese students are intimidated and shrink to authority. Pratt, Kelly \& Wong (1999) and Watkins \& Briggs (2001) confer that the role of a Chinese teacher is highly related to traditional Chinese culture. In order to communicate with students effectively, the teacher must find a balance between authority, responsibility and morality. ICQ, in this way, may provide the balance needed for more effective teacher-student communication. 


\section{Using computer mediated communication (CMC)}

Student initiative is only one of many factors affecting teacher-student communication. Many students may be willing to talk to teachers, but wish to do it anonymously. Yet it is quite difficult for students to complain or to ask for help anonymously in the school environment. Due to inequality of status, it is difficult for free and open communication between teachers and students. Computer mediated communication (CMC) may bridge this gap.

Computer mediated communication has been the focus of interest in communication research since the late 1970s. Much of the early CMC research was based on the assumption that the effects on communication were the results of the characteristics of the media. Early research focused mainly on the competence and efficacy of CMC. Later, researchers compared CMC with face to face communication. The most well known theory in this area is the Social Presence Theory of Short, Williams \& Christie (1976). They defined social presence according to the quality of the medium and argued that the degree of social presence in a particular medium affects people's interaction. They also argued that the degree of social presence of a given medium depends on its capability to transmit information about facial expression including reaction, posture, clothing and other non-verbal cues. Generally speaking, the fewer the cues a medium possess, the weaker the medium's ability to create interpersonal communication. Two years later, Hiltz \& Turoff (1978) reported that in order to compensate for the coldness of CMC, users paid extra efforts to be friendly, sincere and personal. In 1984, Daft \& Lengel (1984) presented the Media Richness Theory. It is similar to the Social Presence Theory, in that both theories agree that different media have different capabilities to provide information. Therefore whether a medium is suitable to a particular task depends on the richness of the information that medium possesses. Many early researchers focused on how interpersonal communication in CMC was affected by the absence of non-verbal cues.

Culnan \& Marcus (1987) reviewed CMC media research extensively, summarising and grouping their findings and named this method of analysing CMC, the Cues-Filter-Out approach, which stresses the characteristics of impersonal communication in the CMC environment. In order to compensate for the coldness of the CMC medium, users make extra efforts to be friendly, warm and personal. Also, as computer mediated messages can be stored and retrieved when needed, users can edit messages prior to sending (Culnan \& Markus, 1987; Walther, 1996). CMC also allows communicators to plan their message more carefully than face to face communication. These characteristics indicate that CMC provides communicators with more freedom in managing interpersonal relationships than does normal communication. 
In the early 1990s, researchers changed their focus of interest to the interpersonal aspect of CMC. Walther (1996) argues that CMC could be impersonal, interpersonal and under certain conditions, hyperpersonal, where hyperpersonal communication describes how CMC relationships lead to a more rewarding relationship than face to face relationships. This theory is capable of explaining how strong relationships are formed in CMC but it does not explain how the context motivates the relational process. This weakness does not affect the framework of this research since the teacher-student relationship already exists. Approaching the millennium, researchers continued to research into the interpersonal aspect of $\mathrm{CMC}$, but began paying more attention to investigating whether or not CMC could serve as a tool to maintain existing relationships, just like teacher-student relationships. Stafford, Kline \& Dimmick (1999) argue that email can be used to support and maintain long distance relationships. Rainie, Fox, Horrigan, Lenhart \& Spooner (2000) found that in comparison with the use of the telephone, email increases contact between family and friends. It is believed by some researchers that "the maintenance of existing relationships is less exotic a topic than the creation of entirely new ones" (Baym, 2002, p.69).

It was found that most research in this field focuses on two distinct areas of interpersonal and online. For example Short, Williams \& Christie (1976) focus on the impersonal aspect of interpersonal communication whereas Walther (1996) focuses on how CMC affects long distance relationships and creates new relationships. These areas are somewhat different from the current investigation, as teacher-student relationships are not newly created. Students meet teachers and schoolmates every day, yet the former still prefer using CMC tools to communicate with the latter. In looking at basic communication in parallel with computer mediated communication, it can be seen that impersonal and interpersonal communication is not discrete, but two ends of the CMC continuum. CMC is a new way of communication, but it still follows the theory of interpersonal communication, as Buber (1970) states communication exists on a continuum, which divides into three levels: I-It, I-You and I-Thou, from impersonal to interpersonal. Wood (2002) asserts that teachers and students often talk personally yet stay within their social roles and do not reveal their private selves, and it is actually in the I-You level. One of the purposes of this study was to see whether it is possible to use ICQ to move teacherstudent communication into a higher level.

From preliminary observations, it appears the characteristics of CuesFiltered-Out and hyperpersonal communication co-exist in teacher-student communication in an ICQ environment. Confucian heritage culture is perceived as the most important factor that affects the behaviour of students in the communication process. This study therefore analysed 
whether ICQ can be used to enhance teacher-student communication. This research is grounded with these three sets of theories. The first of the CMC theories includes the Cues-Filter-Out approach and hyperpersonal communication theory. The Cues-Filtered-Out approach describes media characteristics whereas the hyperpersonal communication theory analyses in which areas $\mathrm{CMC}$ is better than face to face communication. Basic communication theory is compared with CMC theories to gain the "whole picture' in the development of communication theories. This set of theories is used as an indicator to verify the progress of teacher-student communication. The final theory is about Confucian heritage culture; this theory is used to explain the phenomena of teacher-student communication in the ICQ environment. As little research appears to have been done in this area, this research opportunity provided the chance to investigate whether ICQ could be used to enhance teacher-student communication, and to answer:

1. Why students prefer using ICQ to communicate with teachers rather than face to face; and

2. In what way can ICQ be used to enhance teacher-student communication?

\section{Methodology}

This study employed an ethnographic approach to uncover the patterns of teacher-student communication in a CMC environment in two schools of Hong Kong. An ethnographic approach tries to understand and describe the point of view of both teachers and students. Intensive field studies such as careful observations and in depth interviews were conducted to find out the detailed viewpoints of the informants. The research was carried out in three stages:

Stage 1 Semi-structured focus group interviews were used to find out how students perceive face to face teacher-student communication, with the criteria of how do they select a teacher to communicate with and how do they communicate with their parents at home. The data then led to further investigate the communication mode, that is, ICQ's influence on the teacher-student communication.

Stage 2 Using the CMC environment, ICQ messages were used as the means of data collection. In this section, the focus was on investigating ICQ's effect on the relationships of the teacher and student.

Stage 3 The data collected in stage 2 was then categorised and contrasted with similar research results. A group of teachers who were 
experienced in using ICQ to communicate with students were asked to comment on the findings of stage 1 and 2 in order to fulfill the purposes of triangulation of data.

\section{Background of the schools}

Two schools with differing backgrounds were selected as target schools for collecting data. Target School A was a Chinese Medium of Instruction (CMI) Middle Band school. The majority of the students of this school come from lower class families. Many students had low self image, lack of motivation and behaviour problems. Preliminary observations at this school suggest that these students enjoy using ICQ to communicate with their schoolmates, but only a few teachers used CMC tools to communicate with students. Two of the teachers who use ICQ at this school where interviewed in this study. Target School B was a Band One Information Technology pilot school. The IT facilities at this school were well developed and used by both the teachers and students. Both teachers and students were familiar with using CMC tools as a communication channel. The students mainly came from upper class families. These students were found to be self motivated such as organising online study groups to facilitate learning. Many of the teachers at this school acted as facilitators, and ICQ was an important communication tool used in this school, for example one of the teachers interviewed in this study used ICQ discussions to promote the learning of English with her students.

\section{Data collection procedures}

There were two types of interviews conducted, semi-structured face to face focus group interviews, and online interviews. These took place at both research sites, School A and School B. The purposes for focus group interviews were to collect qualitative data using group interaction to obtain information and opinions. For the purpose of selecting the focus interview group members, convenience sampling was employed, that is, those teachers and students using ICQ at both schools. The questions in the focus group interviews were open ended with the aim of ascertaining students' perception of teacher-student communication in the two different schools. Students were encouraged to express their ideas and give comments on other informants' ideas during the focus group interviews. The purposes of the online interviews were to discover why students were willing to disclose more of themselves using this medium and how such disclosure might enhance teacher-student communication. The online interviews began immediately after the focus group interviews.

All focus group informants were potential online informants. They all had an ICQ number and were asked to add the researchers' names to their contact lists. The researchers also asked for their ICQ numbers to be sent to 
schoolmates on their contact list so that their peers could also approach them through ICQ. Unless the online informants provided their real names proactively, the researchers did not know the informants, leaving the students to choose whether or not to disclose their identities creating a comfortable atmosphere that allowed for higher degrees of self disclosure.

The purpose of the teacher focus group interview was for triangulation. The teachers, two from each school, were asked to express their opinions on using ICQ to communicate with students to collect data from different perspectives. Teachers who were experienced in using ICQ to communicate with students were asked to attend the interview. The questions in this interview were semi-structured according to the information obtained in the student focus group interviews and online interviews. Teachers were asked to comment on the students' behaviours in the ICQ environment and suggest possible explanations for such behaviours. Data collection in the teacher focus group interview was similar to that of student focus group interviews, which included document analysis and data analysis of ICQ transcripts. The purpose of document analysis was to collect supplementary data to support the research arguments. The purpose of the data analysis was to identify trends and patterns in the students' answers.

However the information provided by the students was only raw data and it was necessary to transcribe this to provide detailed records to enable analysis. Asking simple questions initially broke down data, and the results were compared. Similar findings were grouped together. The data from the online interviews was in text format and translated into English for coding. According to Culnan \& Marcus (1987) and Walther (1996), communication in the CMC environment can be categorised into two types, that of impersonal and interpersonal. Therefore the data obtained in this research was categorised into these two categories, as impersonal and interpersonal characteristics were found to co-exist in the ICQ online interviews. All data was also categorised into four factors: 1) the school factor; 2) the student factor; 3) the teacher factor and 4) the parental factor. These results were used to answer the two research questions.

\section{Results and discussion}

Interviews were conducted with 11 informants face to face then through ICQ online with four students. Four teachers who used ICQ to communicate with students were also interviewed. An overview of these informants is given in the Appendix. The student focus group interviews were carried out before the end of March 2003, but due to the outbreak of SARS in Hong Kong, some students were not able to attend the interviews. The number of informants for the focus group interviews was less than the number planned. Only six students of School A and five students of School 
B were able to attend the student focus group interviews. Formal online interviews were carried out in April 2003. After careful observation and preliminary communication, four students were selected to be online informants. It was found that most student focus group informants were very keen to provide their opinions, but they only focused on personal beliefs, such as how they found the school environment not suitable for teacher-student communication. When the questions related to peers, individual students or teachers, the student informants hesitated to provide further information. Yet both impersonal and interpersonal characteristics of communication were to be found in the online interviews Of the data collected in the online interviews, $43 \%$ was classified to contain impersonal characteristics and $57 \%$ was classified to contain interpersonal characteristics.

Some online informants were able to establish very good communication with teachers through ICQ. It was also observed that students from School A, the lower band school, found it easier to establish good communication than did students from School B, which was the higher band school, when using ICQ. The reason appeared to be that most School A students came from lower socio-economic families and it was hard for their parents to look after them, at the same time, they had little pocket money and therefore needed to stay at home after school and to entertain themselves, which included chatting with friends or teachers on ICQ. Since they were lacking parental supervision and concern, once they found that teachers were willing to chat with them in ICQ, it was easier to build up better teacher-student communication this way. Contrary to that, most students from School B had a relatively high socio-economic status, were more target oriented, and tended to use ICQ for more instrumental purposes. For example, they would use ICQ to ask the teachers academic related questions, therefore the purpose of using ICQ for teacher-student communication was different in School B compared with School A.

From our observations and the data collected, both male and female students were willing to talk privately with the teachers using ICQ, but male students were more proactive in sharing their feelings, with over $60 \%$ of the male students in the researchers' ICQ contact list willing to talk privately, but less than $30 \%$ of female students were willing to do so. The boys who were very shy in face to face communication tended to be totally different in ICQ, sometimes proactively sharing their thoughts and emotions. For example, informant A-SFG-6 who could be classified as an introvert student, as he seldom expressed ideas in class or the focus group interviews, approached teachers proactively in ICQ and was very helpful when it came to assisting teachers to design a subject web page. 
The data collected from the student focus group interviews, online interviews and transcripts, helped answer the first research question: "Why do students prefer using ICQ rather than communicating face to face with teachers?" This may be discussed with reference to four factors: 1) the school factor; 2) the student factor; 3) the teacher factor and 4) the parental factor.

\section{The school factor}

First, there was the school factor. The basic concept of schools and the mission of the education policy of Hong Kong do not consider the need for teacher-student communication within schools. Therefore most of the schools in Hong Kong only focus on academic achievement and policies are set according to this mission. The physical layout of school does not facilitate teacher-student communication. The students felt that the school was not a suitable place to conduct private talks with teachers. The limitations of time and place were perceived as important factors affecting teacher-student communication. The personalities of the students, the culture of the school, and the degree of teacher willingness to support students also contributed to low teacher-student communication within school. Some informants claimed that "most teachers would talk to us in the corridor" and obviously, the corridor is not a suitable place for personal communication. Yet most schools in Hong Kong have no suitable area for teacher-student communication of a personal nature; students would rather "prefer using ICQ to talk teacher". From the data obtained from the online interviews, it was found that teacher-student communication in the ICQ environment surpassed daily teacher-student communication in school environments. For example students would give comments on teachers' performance in ICQ but they would never do so in the face to face environment. This finding matches the argument put forward by Walther (1996). To illustrate this point informant A-OI-1 was critical of some teacher's ability to use IT but did not criticise teachers openly because it is very impolite and may have implications.

\section{The student factor}

Secondly, there was the student factor. From the data collected during the interviews, it was found students' performance was greatly affected by their peer group. Some peers regarded talking with teachers as flattering. In a Confucian heritage culture, students are generally passive. The safest way to avoid making mistakes and thus being laughed at is to keep silent in school. Students use a "face saving" methodology by not criticising peers' work in front of the class. Also students avoid talking to teachers at school in order to conform to their group norms. Even when students believe they are right they do not persist, because obedience and conformity are the 
norm values of their peer group. Such thinking is due to the collectivism emphasised by Confucian heritage culture. These Chinese students believed that they should be loyal to their peers, even when students know that their friends have done something wrong, they will not tell teachers directly or openly. In order to maintain group harmony, Chinese students avoid conflict by conforming to the peer norms. Therefore it is rare for students to approach teachers individually in the school.

In this situation, students needed an alternative means of communication with teachers. ICQ provided a good channel for these students to communicate with their teachers because ICQ balanced the need of "loyalty to friends" with the need to "do the right thing". For example, the online informant (B-OI-2) who used a nickname to communicate with the researchers and claimed to be a girl was probably a student in Form 4 because she discussed the behaviour of some students in a class in Form 4 . Communication with this informant was not continuous or two way. Most of the time of the time she left offline messages in ICQ. Her messages were very target oriented, revealing who was going to cheat in tests and other facts. On the one hand, she wanted to disclose the misbehaviours of her classmates but on the other hand she would like to keep her identity secret so as not to be named as a traitor. This raises another point discussed at the focus teacher interviews and leads onto the third factor, that is, how teachers should deal with such communication, and was ICQ allowing students to openly communicate in a "face saving" way.

\section{The teacher factor}

Third, there was the teacher factor. Traditionally, teachers are perceived as a symbol of authority, a source of knowledge and a model to imitate. Now, due to the development of information technology, this superior status is being challenged. Teachers' proficiency with IT is an important factor affecting student-teacher communication. Sometimes, according to the student informants, the teacher's lack of IT proficiency is a barrier to good communication. Also, the teachers' willingness to use ICQ to communicate with students was significant. In School A only a few teachers used ICQ whereas in School B over 80\% of teachers used ICQ to communicate. When this point was discussed in the teacher focus group it was understood to be seen as a matter of "face saving", as some teachers disliked the fact that students are more capable than they are in handling IT tools, and therefore avoided using ICQ to talk to students. One informant (A-OI-1) claimed that a sizable number of his classmates believed their teachers were not willing to communicate with them through ICQ because they have poor IT competency and do not want the students to know this. He believed that teachers did not want to give their ICQ numbers to students, not because of limited time but because of insufficient teacher confidence in manipulating 
such CMC tools. School B also had the advantage of being an Information Technology pilot school; therefore technology had been seen as a means of communication and pedagogical change for these teachers whereas School A did not have this advantage.

If such "challenges" from students were redirected to a "proper channel of communication', teachers would be able to develop a deeper relationship with students. The students who felt their teachers were concerned about them would be more willing to talk at the initial stage of their problems. Therefore this kind of "challenge" should be regarded not as a crisis but rather as a chance to establish good communications with students. There was a consensus between the students that it is very important to know teachers; not all teachers, but those with whom students wish to communicate. The main reason to get to know teachers was not curiosity, it was need. Students needed to find out whether "teachers practise what they preach". The informants said they required a very high standard of their teachers, who are not only "teachers"; but also "role models". Students only communicated with teachers who fulfilled their requirements. This study found these students are not going to confront teachers, since teachers are seen as "models" or "standards". These students merely wish to clarify whether these "models" and "standards" are worth following.

The students also wanted to find out whether teachers' actions suit their words, and whether their behaviour in school was consistent with their behaviour in daily life. They also wanted to know more about teachers' personalities. On the one hand students wanted teachers to be authoritative, with the dignity and power to control the class, yet on the other hand they wanted their teachers to be soft and humorous: to be able to jest and have fun. Though most informants agreed that it is hard for teachers to jest with them in the school, they only communicated with those teachers who possessed both requirements. In the Confucian heritage culture, the teacher is an authority figure positioned at the highest level of the social hierarchy. Therefore it is hard for students to communicate freely with teachers in school. In the ICQ environment the teacher is just a member of the cyberworld who does not have a hierarchical social status, thus this research found that these teachers and students could communicate with each other on the same level.

\section{The parental factor}

Fourth was the parental factor. Informants claimed that Chinese parents are quite conservative and find difficulty in expressing their feelings. Therefore students never know their parents' thoughts and feelings. Parents complained over minor things and whenever the informants had free time the parents wanted them to study or revise. Consequently these students 
were spending time on the computer, pretending to do their homework when in reality they were using ICQ to send messages to their classmates. Since their parents were not as computer literate, they were not aware of what their children were actually doing. Hong Kong education is dominated by examinations and parents, teachers and students are under pressure to focus on examination results, at the expense of students' individual needs. It was found that these students do not communicate with their parents because they thought that their parents would not understand their situation. Also it was hard for students to communicate with their friends because many of their friends are also their competitors in the classroom. A channel therefore was needed to help students release pressure by expressing their feelings. This research found that ICQ was the most commonly used "channel" through which these students were fulfilling their individual needs.

These four factors helped explain why students prefer using ICQ to communicate with teachers rather than communicating face to face. Underlying these factors were both remote and immediate causes. The remote cause being that students are under pressure from their Confucian heritage and need to release this pressure, the immediate cause being the emergence of information technology like ICQ provides a channel through which teachers and students can have the opportunity to communicate freely.

The data collected in the online interviews and data analysis of ICQ transcripts provided answers to the second research question: "In what way can ICQ be used to enhance teacher-student communication?" Seven important findings about the use of ICQ are discussed below.

\section{ICQ finding 1}

The first finding was that ICQ is able to cater for students with verbal communication difficulties. This could be classified as an impersonal characteristic. Students have different personality characteristics, so the shy and timid students tended to hesitate to communicate with teachers face to face in school. Yet some students with difficulties in verbal communication were quite active in ICQ and even approached teachers proactively when online. One of the students claimed that "they don't know why but they would felt very tense when talking to teachers face to face since they are not good at conveying themselves clearly". The characteristics of ICQ provided students with the opportunity to plan and edit their messages and so remove the fear of failure. Chinese children are relative weak verbally compared to their nonverbal ability (Hiemstra, 1982) and ICQ allowed these communicators to plan their message more carefully, thereby helping those with verbal communication difficulties. 


\section{ICQ finding 2}

The second finding was that ICQ is able to cater for the need for anonymity. This could be classified as an impersonal characteristic. Students who used nicknames to communicate with their teachers on ICQ were more willing to provide information, than those whose identities were known. Also they were more willing to comment on teachers' performances under the veil of anonymity. It was found that attempts to discover the real names of the students resulted in the termination of the communication. Therefore teachers who use ICQ should respect the use of nicknames as this provides an anonymity that can enhance communication. Anonymity reduces the salience of group norms, so communicators are more willing to talk if their identities are not evident. But this also offers a challenge to teachers who must deal with what might be discussed, openly and honestly. During the data collection it was found that the students using ICQ frequently changed their nicknames, especially those who perceived themselves as problem students. Sometimes they just changed the nickname but used the same ICQ number. Sometimes they changed both the nickname and ICQ number and used a new identity. In this way, ICQ provides a channel for students who lack academic satisfaction, or are unable to cope with studies, or have poor relationships with teachers, to "turn over a new leaf" and build a "new" relationships with teachers. It was observed, in this research, that "problem students" behaved better in class after communicating with teachers anonymously. Therefore it is proposed on the basis of this finding that anonymous communication can help repair poor teacher-student relationships.

\section{ICQ finding 3}

The third finding was that ICQ is able to cater for sexual differences. This could be classified as an interpersonal characteristic. In this research it was found that male students were more proactive in sharing their feeling with teachers in ICQ (about $80 \%$ of the male students in the researchers' ICQ contact list) while female students (about $50 \%$ of the female students in both target schools A and B) were more proactive in face to face communication. A general trend was noted from the data that the boys were shy in face to face communication, but they became very proactive and shared their private thoughts while in ICQ, whereas the girls were more proactive in talking to the teachers in the two schools, but focused on academic related matters or just gossip about their schoolmates on ICQ. This might be explained by the Confucian heritage culture, where boys are valued more than girls, are trained to be tough and not to show their true feelings openly. For example, informant A-SFG-4 claimed his classmates would laugh at him if they knew he could not solve problems by himself. Therefore Chinese boys tend bury their feelings in order not to be 
perceived as weak, and choose the "face saving" method of ICQ to express their feelings or to talk about problems with teachers. The research data gathered supported this statement.

\section{ICQ finding 4}

The fourth finding was that ICQ is able to provide a feedback mechanism for teachers. This could be classified as an interpersonal characteristic. Confucian heritage culture has resulted in the teaching style of most Hong Kong teachers being unidirectional. It is rare for teachers to receive feedback on their teaching from students, but in ICQ students were found to be willing to comment. In the ICQ environment, status and position cues were reduced; students were found to be more open in giving comments to their teachers. ICQ, as suggested by this research, provides a channel for teachers to better understand themselves and reflect openly on their own processes.

\section{ICQ finding 5}

The fifth finding was that ICQ is able to provide a mutual support mechanism between teachers and students. This could be classified as an interpersonal characteristic. As the participant researcher, it was found that ICQ communication was not only beneficial to students but also beneficial to other teachers. ICQ was found to be a powerful tool through which teachers can enter the world of the student, cross the generation gap and know the latest adolescent trends and happenings. In ICQ the students treated the teachers as peer members and sent them things such as MP3 songs. This was very helpful in analysing the sub-culture of the students. The online interviews were carried out during the outbreak of SARS in Hong Kong and during this time not only did students send lots of information about SARS to the researchers, they also showed their concern for their teachers' well being. From this mutual support, trust developed between the teacher and students. It was found in this research, that through providing teachers with information, students gained a sense of achievement and a more positive self image of "doing the right thing".

\section{ICQ finding 6}

The sixth finding was that ICQ is able to provide continuous support. This could be classified as an interpersonal characteristic. This research found that ICQ provides a source of teacher help whenever it may be required by students, and especially during holidays. It was not necessary for teachers to be online all the time, because students can leave offline messages. It was found that most students do not have an immediate need; they merely need a sympathetic ear. Students are eager to get support from teachers through this method, even though it may be just a few words. Students 
claimed that all they needed was phrases like "keep it up", or "I think you have the ability"; words they never hear from teachers in school. One student claimed he liked "reading messages of support from teachers over and over again when he was down as this helped greatly". In this way, it was found that ICQ provides a channel for teachers to offer continuous support to students.

\section{ICQ finding 7}

The final finding was that ICQ is able to provide freedom of control. This could be classified as an impersonal characteristic. Teacher-student communication within the school is hierarchical with students unable to control the time or content. Sometimes teachers spend a lot of time talking to students and students may find this annoying. In ICQ it was found to be different. In ICQ the students have the control, they can choose to communicate or not communicate with teachers, according to their own wishes and in their own time. Therefore whenever they communicate with teachers online, they are proactive. It was found that due to the diminished verbal cues, ICQ users are less aware of the hierarchical status of the communication partners than those engaged in face to face communication. The status of the communicators is thus equalised. This study found that these students prefer using ICQ to communicate with teachers because they have the control over the communication process and are equal rather than subordinate partners.

These seven findings explained, and above all supported positively: "In what way can ICQ be used to enhance teacher-student communication?" These questions and answers are based on the research findings derived from data collected during the interviews and we believe that the function of teacher-student communication using ICQ can extend far beyond these seven findings.

\section{Conclusion}

Ironically, the Internet has increased and not depressed communication amongst young people. Teenagers in Hong Kong are now facing a dilemma: on the one hand they are fixed with Confucian heritage cultural beliefs, and on the other hand they are impacted by Western culture which emphasises individual values. The Chinese heritage culture and hierarchy frames the student's role, relationships with others, and the actions they take, and it is assumed students should give teachers their due respect. The Chinese mentality is characterised by their pursuit of harmony and in order to maintain group harmony, students avoid directly expressing their point of view; they suggest their ideas rather than voice them out directly, since expressing their ideas directly is seen as too individualistic. It has been 
found that in order to express their ideas individually, Hong Kong students have to utilise other channels, such as CMC tools like ICQ, to fulfill these needs. In this study the use of ICQ was found to help students communicate better with teachers without the Confucian heritage cultural constraints. It was found that students prefer using ICQ to communicate with teachers and four factors influenced this: the school, the teacher, the students, and the parents. It was also found that seven findings supported the reasons why ICQ can be used to enhance teacher-student communication. ICQ provides a channel through which teachers and students can communicate freely, and it was shown in this research within two Hong Kong schools, that ICQ is a tool which can help students resolve their communication dilemmas. While the low numbers are acknowledged in this current study, these results are an indication of what was happening in these two Hong Kong secondary schools where students and teachers were using ICQ. Further research will be carried out within other secondary schools to validate the data but some valuable research findings have been made here in this initial study. It is intended to conduct a crosscultural comparison study with Western students in Australia to compare the results from these Chinese informants to further understand the use of ICQ between different cultures and using CMC to enhance teacher-student relationships.

\section{References}

Baym, N. (2002). Interpersonal life online. In L. Lievorouw \& S. Livingstone (Eds), Handbook of new media: Social shaping and consequences of ICTs. (pp. 62-76). London: Sage.

Buber, M. (1970). I and thou. (Walter Kaufmann, Trans). New York: Scriber.

Culnan, M.J. \& Markus, M.L. (1987). Information technologies. In F.M. Jablin, L.L. Putnam, K.H. Roberts \& L.W. Porter (Eds), Handbook of organizational computing: An interdisciplinary perspective. (pp. 420-43). Newbury Park, CA: Sage.

Daft, R.L. \& Lengel, R.H. (1984). Information richness: A new approach to managerial behavior and organizational design. In L.L. Cummings \& B.M. Staw (Eds), Research in organizational behavior 6, (pp. 191-233). Homewood, IL: JAI Press.

Hiemstra, G. (1982). Teleconferencing, concern for face, and organizational culture. In M. Burgoon (Ed), Communication yearbook 6. (pp. 874-904). Beverly Hills, CA: Sage.

Hiltz, S.R. \& Turoff, M. (1978). The network nation: Human communication via computer. Reading, MA: Addison-Wesley.

Ho, D. Y. (1994). Cognitive socialization in Confucian heritage cultures. In P. Greenfield \& R. Cocking (Eds), Cross-cultural roots of minority child development (pp. 285-314). Hillsdale, NJ: L. Erlbaum Associates. 
Ho, Y. F., Peng, S. Q. \& Chan, S. F. (2001). Authority and learning in Confucianheritage education: A relational methodological analysis. In C. Y. Chiu, F. Salili, F. Salili \& Y. Y. Hong (Eds), Multiple competencies and self-regulated learning: Implications for multicultural education (pp. 29-47). Greenwich, CT: Information Age Pub.

Li, J. (1995). Yuan yuan liu chang de ru dao si xiang. Shen Yang: Liao Ning Gu Ji.

Pang, E. (2000). Filial piety in modern time: The ideal and practice of parental care. Paper presented at International Conference on Searching for Meaning in the New Millennium, 13-16 July, Vancouver, BC, Canada [viewed 15 Aug 2004, verified 1 Sep 2005] http:/ / www.meaning.ca/pdf/2000proceedings/elaine_pang.pdf

Rainie, L., Fox, S., Horrigan, J., Lenhart, A. \& Spooner, T. (2000). Tracking online life: How women use the Internet to cultivate relationships with family and friends. Washington, DC: Pew Internet and American Life Project. http: / / www.pewinternet.org/PPF/r/11/report_display.asp

Pratt, D. D., Kelly, M. \& Wong, W. S. (1999). Chinese conception of 'Effective Teaching' in Hong Kong: Towards culturally sensitive evaluation of teaching. International Journal of Lifelong Education, 18(4), 241-258.

Short, J., Williams, E. \& Christie, B. (1976). The social psychology of telecommunications. New York: John Wiley.

Stafford, L., Kline, S.L. \& Dimmick, J. (1999). Home e-mail: Relational maintenance and gratification opportunities. Journal of Broadcasting and Electronic Media, 43(4), 659-69.

Tu Po Ji Gou (2000). Qing shao nain wang shang xin jie wang luo xing wei yan jiu. Xiang-gang: Tu Po Ji Gou.

Walther, J.B. (1996). Computer-mediated communication: Impersonal, interpersonal and hyperpersonal interaction. Communication Research, 23(1), 3-43.

Watkins, D. A. \& Biggs, J. B. (2001). The paradox of the Chinese learner and beyond. In D.A. Watkins \& J. B. Biggs (Eds), Teaching the Chinese learner: Psychological and pedagogical perspectives. Hong Kong: Comparative Education Research Centre, The University of Hong Kong.

Wood, J. T. (2002). Interpersonal communication: Everyday encounters (3rd ed.). Belmont, CA: Wadsworth.

\section{Appendix: Basic information about the informants}

\begin{tabular}{|c|c|c|c|l|}
\hline & $\begin{array}{c}\text { Infor- } \\
\text { mant }\end{array}$ & $\begin{array}{c}\text { Gen- } \\
\text { der }\end{array}$ & Level & \multicolumn{1}{|c|}{ Description } \\
\hline $\begin{array}{c}\text { School } \\
\text { A } \\
(\mathrm{n}=6)\end{array}$ & A-SFG-1 & F & S6 & $\begin{array}{l}\text { This student had used ICQ to communicate with } \\
\text { the teacher since she was in S2 }\end{array}$ \\
\cline { 2 - 6 } & A-SFG-2 & F & S2 & $\begin{array}{l}\text { This student was very skillful in using ICQ and } \\
\text { approached teachers proactively from within ICQ. }\end{array}$ \\
\cline { 2 - 6 } & A-SF-3 & M & S4 & $\begin{array}{l}\text { This student had good academic results but was } \\
\text { pressurised by his parents to achieve higher } \\
\text { results. }\end{array}$ \\
\hline
\end{tabular}




\begin{tabular}{|c|c|c|c|c|}
\hline & A-SFG-4 & $\mathrm{M}$ & S4 & This student was a good friend of A-SFG-3. \\
\hline & A-SFG-5 & $\mathrm{M}$ & S2 & $\begin{array}{l}\text { This student never approached teachers in the } \\
\text { school but was very active on ICQ }\end{array}$ \\
\hline & A-SFG-6 & $\mathrm{M}$ & S2 & $\begin{array}{l}\text { This student was an introvert. He seldom } \\
\text { expressed ideas in the focus group interviews but } \\
\text { was very helpful and approached teachers } \\
\text { proactively in ICQ. }\end{array}$ \\
\hline $\begin{array}{c}\text { School } \\
\text { B } \\
(\mathrm{n}=5)\end{array}$ & B-SFG-1 & $\mathrm{F}$ & S2 & $\begin{array}{l}\text { This student was the class monitor. She came from } \\
\text { mainland China four years ago and had good } \\
\text { academic results but seldom communicated with } \\
\text { teachers. }\end{array}$ \\
\hline & B-SFG-2 & $\mathrm{F}$ & S2 & $\begin{array}{l}\text { This student was a good friend of B-SFG-1. She } \\
\text { had excellent academic results, and also came from } \\
\text { Mainland China a few years ago. }\end{array}$ \\
\hline & B-SFG-3 & $\mathrm{M}$ & S4 & $\begin{array}{l}\text { This student was a repeat student. He was very } \\
\text { good at dancing and programming. He was also } \\
\text { one of the online informants (B-OI-1). }\end{array}$ \\
\hline & B-SFG-4 & $\mathrm{F}$ & S4 & $\begin{array}{l}\text { This student had average academic results and } \\
\text { was active in ICQ. }\end{array}$ \\
\hline & B-SFG-5 & $\mathrm{F}$ & S6 & $\begin{array}{l}\text { This student was very intelligent and had a good } \\
\text { relationship with the teachers at school. }\end{array}$ \\
\hline $\begin{array}{l}\text { Online } \\
\text { inter- }\end{array}$ & A-OI-1 & $\mathrm{M}$ & S4 & $\begin{array}{l}\text { This student had some problems with his parents } \\
\text { but he was good academically. }\end{array}$ \\
\hline $\begin{array}{c}\text { views } \\
(\mathrm{n}=4)\end{array}$ & A-OI-2 & $\mathrm{F}$ & S6 & $\begin{array}{l}\text { This student was a good friend of A-SFG-1. She } \\
\text { entered School A, Middle Band to continue her } \\
\text { studies, having previously attended a Band One } \\
\text { school. }\end{array}$ \\
\hline & B-OI-1 & $\mathrm{M}$ & S4 & Same as B-SFG-3 \\
\hline & B-OI-2 & $\mathrm{F}$ & S4 & $\begin{array}{l}\text { This student used a nickname when } \\
\text { communicating with the teacher. She provided } \\
\text { much useful information to the researchers. }\end{array}$ \\
\hline $\begin{array}{l}\text { Teac- } \\
\text { hers }\end{array}$ & A-TFG-1 & $\mathrm{M}$ & N.A. & $\begin{array}{l}\text { This teacher of Chinese was experienced IT user } \\
\text { and an experienced user of ICQ }\end{array}$ \\
\hline$(\mathrm{n}=4)$ & A-TFG-2 & $\mathrm{F}$ & N.A. & $\begin{array}{l}\text { This teacher of Chinese had an adequate } \\
\text { knowledge of IT and a willingness to accept new } \\
\text { ideas. }\end{array}$ \\
\hline & B-TFG-1 & $\mathrm{M}$ & N.A. & $\begin{array}{l}\text { This teacher of Religion was quite demanding but } \\
\text { most of his students gained good results in public } \\
\text { examinations. }\end{array}$ \\
\hline & B-TFG-2 & $\mathrm{F}$ & N.A. & $\begin{array}{l}\text { This experienced teacher of English created } \\
\text { discussion forums in ICQ which students learnt } \\
\text { English. }\end{array}$ \\
\hline
\end{tabular}

Shung King Yin (Suky), The University of Hong Kong, Hong Kong Email: sukyshung@hongkong.com

Associate Professor Sue Trinidad, Faculty of Education, Languages Studies and Social Work, Curtin University of Technology, PO Box U1987, Perth WA 6845, Australia. Email: S.Trinidad@curtin.edu.au` 